\title{
Electrodeposition of nickel using eutectic based ionic liquids
}

\author{
A. P. Abbott*, K. El Ttaib, K. S. Ryder and E. L. Smith
}

The electrolytic deposition of nickel is demonstrated using a solution of the metal chloride salt separately in either a urea or ethylene glycol/choline chloride based ionic liquid. It is shown that the deposition kinetics and thermodynamics differ from the aqueous processes and these result in different deposit morphologies. It is also shown for the first time that bright metal coatings can be obtained from these liquid systems by adding various brightening agents and deposits can be put directly onto substrates such as aluminium without prior treatment. The general mechanism by which brighteners function in ionic liquids is also discussed.

Keywords: Electrodeposition, Nickel, Ionic liquid, Eutectic, Brighteners

\section{Introduction}

The electrodeposition of numerous metals and alloys has been demonstrated using a variety of ionic liquids with both discrete and complex anions. Numerous reviews have been published on metal deposition using ionic liquids ${ }^{1-5}$ and a recent book ${ }^{6}$ provides an authoritative summary of the area. The advantages of these novel solvents include: electroplating electronegative metals, e.g. Al, Ta, Nb, Mo, W; direct electroplating of metals on water sensitive substrate materials such as $\mathrm{Al}$ and $\mathrm{Mg}$ can be achieved, removal of hydrogen embrittlement from the substrate; alloy deposition is easier to achieve; the possibility exists to develop novel immersion plating baths; potential energy savings compared with aqueous solutions; replacement of many hazardous and toxic materials currently used in water, e.g. $\mathrm{Cr}(\mathrm{VI})$, cyanide; and access to novel deposit morphologies.

While the majority of important metals have been studied in these solvents, one obvious omission is the deposition of nickel. Gou and $\operatorname{Sun}^{7}$ have recently studied the electrodeposition of nickel and nickel-zinc alloys from the zinc chloride-1-ethyl-3-methylimidazolium chloride. They found that although $\mathrm{NiCl}_{2}$ dissolved in the pure chloride rich 1-ethyl-3-methylimidazolium chloride ionic melt, metallic nickel could not be obtained by electrochemical reduction of this solution. The addition of zinc chloride to this solution enabled the electrodeposition of dense, compact and adherent nickel coatings.

It has recently been shown that ionic liquids can be formed from eutectic mixtures of a quaternary ammonium salt such as choline chloride $(\mathrm{ChCl})$ with a hydrogen bond donor species such as a glycol, amide ${ }^{8}$ or carboxylic acid. ${ }^{9}$ These liquids have been used for the deposition of a range of metal coatings including $\mathrm{Zn},{ }^{10}$

Department of Chemistry, University of Leicester, Leicester LE1 7RH, UK

*Corresponding author, email apa1@le.ac.uk
$\mathrm{Cr}, \mathrm{Sn},{ }^{10} \mathrm{Cu}$ and $\mathrm{Ag},{ }^{11,12}$ and for metal dissolution processes such as electropolishing. ${ }^{13,14}$

Here, the electrolytic deposition and morphologies of metallic Ni coatings from ionic liquids (IL) based on a $\mathrm{ChCl}$ :2 ethylene glycol (EG) (Ethaline) and a $\mathrm{ChCl}: 2$ urea (Reline) eutectic mix were investigated. Changes in morphology and composition have been investigated by the addition of brighteners and changing the IL used in the deposition process. Cyclic voltammetry (CV) and chronocoulometry together with AFM and SEM were used to probe the mechanism of deposition and the structure of the Ni deposits.

\section{Experimental details}

\section{Preparation of IL}

Choline chloride $\left[\mathrm{HOC}_{2} \mathrm{H}_{4} \mathrm{~N}\left(\mathrm{CH}_{3}\right)_{3} \mathrm{Cl}\right](\mathrm{ChCl})$ (Aldrich $99 \%$ ) was recrystallised from absolute ethanol, filtered and dried under vacuum. Urea (Aldrich $>99 \%$ ) was dried under vacuum before use. Ethylene glycol (EG) (Aldrich 99+\%), nickel chloride dihydrate, ethylenediamine (en) and acetylacetonate (acac) (all Aldrich) were all used as received. The eutectic mixtures were formed by stirring the two components together, in the stated proportions, at $75^{\circ} \mathrm{C}$ until a homogeneous, colourless liquid formed.

\section{Electrochemical and analytical}

Voltammetry and potential step experiments were carried out using an Autolab PGSTAT12 potentiostat controlled with GPES software. A three electrode system consisting of a platinum microelectrode $(0.5 \mathrm{~mm}$ diameter $)$, a platinum counter electrode and a silver wire reference electrode was used. The working electrode was polished with $0 \cdot 3 \mu \mathrm{m}$ alumina paste, rinsed and dried before all measurements. All voltammograms were performed at ambient temperature $\left( \pm 22^{\circ} \mathrm{C}\right)$ and at various scan rates from 10 to $50 \mathrm{mV} \mathrm{s}^{-1}$. Surface analysis was carried out using a Digital Instruments Nanoscope IV Dimension 300 (Veeco) atomic force microscope with a $100 \mu \mathrm{m}$ 

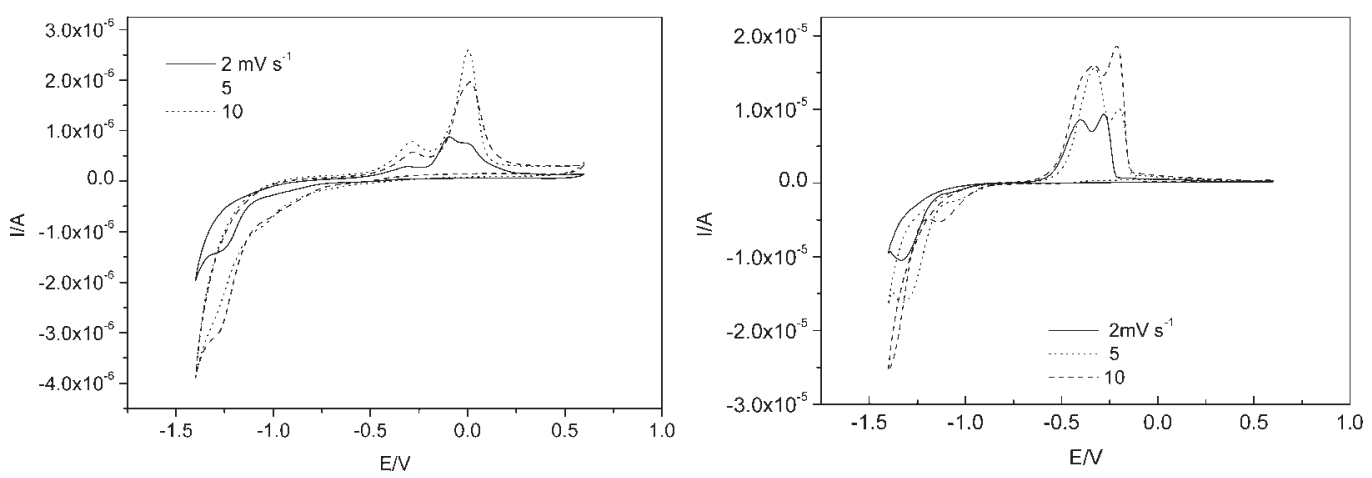

1 Cyclic voltammetry of $0.2 \mathrm{M} \mathrm{NiCl} 2 \cdot 6 \mathrm{H}_{2} \mathrm{O}$ in $\mathrm{ChCl}: 2 \mathrm{EG}$ (right) and $\mathrm{ChCl}: 2$ urea (left) IL at $20^{\circ} \mathrm{C}$ on $\mathrm{Pt}$ electrode as function of sweep rate

scanning head and run using both contact and tapping (resonant) modes. Images were acquired in air.

All voltammetric experiments carried out with deep eutectic solvent (DES) based on ethylene glycol and urea have been carried out using a silver wire quasi-reference electrode. The reference potential of the silver wire has been shown to be dominated by the activity of the chloride ion in ionic liquid environments and the chloride concentration is considerably larger than that of any other species in solution. Copper substrates used for the bulk $\mathrm{Ni}$ deposits were etched with $5 \%$ aqueous $\mathrm{HCl}$, rinsed with distilled $\mathrm{H}_{2} \mathrm{O}$, dried and then sonicated in acetone.

\section{Results and discussion}

\section{Cyclic voltammetry of $\mathrm{Ni}(\mathrm{II})$ in $\mathrm{ChCl}: 2 \mathrm{EG}$ and ChCl:2urea IL}

Figure 1 shows the cyclic voltammograms for the reduction of $0 \cdot 2 \mathrm{M} \mathrm{NiCl} 2 \cdot 6 \mathrm{H}_{2} \mathrm{O}$ in a $\mathrm{ChCl}: 2 \mathrm{EG}$ and a $\mathrm{ChCl}$ :2urea IL at $20^{\circ} \mathrm{C}$ on a Pt electrode as a function of sweep rate. It is clear that the reversibility of the deposition process is different in the two liquids. In the EG eutectic, the difference between the onset voltage of deposition and the onset of dissolution is smaller than in the urea eutectic. The authors propose that this is due to differences in ligand activity between the two liquids. There is a strong coordination between the urea and chloride ions which effectively decreases the activity of chloride compared with EG.

Figure 1 also shows that the deposition is quasireversible in both liquids. The electrochemistry of most $p$ and $d$ block elements has been studied in both of these liquids and the authors have found that metals in groups 3-5 (Sc-V) cannot be deposited within the potential window of the ionic liquid. Those in groups $6-8(\mathrm{Cr}-\mathrm{Fe})$ can be reduced but not stripped whereas $\mathrm{Co}, \mathrm{Ni}$ and $\mathrm{Pd}$ all give a quasi-reversible deposition response. The majority of the remaining elements $(\mathrm{Cu}, \mathrm{Ag}, \mathrm{Zn}, \mathrm{Hg}$, In, $\mathrm{Sn}$ and $\mathrm{Bi}$ ) show reversible deposition and stripping responses. The reason behind this is not known but is thought to result from the speciation of the metal complexes in solution. Metals in periods 3-8 predominantly have octahedral complexes whereas those in groups 11-15 tend to form linear or tetrahedral species. The quasi-reversible metals such as $\mathrm{Ni}$ are variable and tend to be either square planar or octahedral depending upon the ligand.

Determining speciation in ionic liquids is not trivial because it is impossible to evaporate the solvent to leave the metal complex. One method that has previously been used is fast atom bombardment mass spectrometry (FABMS). FABMS for the $\mathrm{ChCl}$ :2EG IL containing $\mathrm{NiCl}_{2} \cdot 6 \mathrm{H}_{2} \mathrm{O}$ shows that the only ionic $\mathrm{Ni}$ containing species is $\mathrm{NiCl}_{3}{ }^{-}$. No cationic $\mathrm{Ni}$ species were observed showing that the naked or hydrated ions are not stable in solution. While this is unusual, it is the same as that observed for most metal complexes obtained by dissolving metal halides in these types of ionic liquids. When a metal salt of the form $\mathrm{M}^{\mathrm{x}+} \mathrm{Cl}_{\mathrm{x}}$ is dissolved in an ionic liquid, FABMS always shows that the predominant species is $\mathbf{M}^{\mathrm{x}+} \mathrm{Cl}_{\mathrm{x}+1}$. This may however be an artefact of the ionisation technique which will destroy any weak complexes. Interestingly, FABMS also shows the cluster $\mathrm{ChCl}_{2}{ }^{-}$but no $\mathrm{Cl} . \mathrm{EG}^{-}$whereas in the urea based liquid, the $\mathrm{ChCl}_{2}{ }^{-}$cluster is small but the Cl.urea ${ }^{-}$is the largest signal confirming the fundamental difference between the chloride speciation.

The reduction process is difficult to quantify but the onset potential is ca. $-1 \cdot 1 \mathrm{~V} v$. Ag. Comparison with the aqueous redox couple is difficult owing to the difference in speciation but $E^{0}\left(\mathrm{Ag}^{+} / \mathrm{Ag}^{0}\right)-E^{0}\left(\mathrm{Ni}^{2+} / \mathrm{Ni}^{0}\right)=1 \cdot 03 \mathrm{~V}$. What is notable about the Ni redox process is that the potential for the onset of reduction differs from that for oxidation by $\sim 0.5 \mathrm{~V}$. The reduction waves are not clearly defined like those previously observed with other metals such as $\mathrm{Cu}$ in the same IL and the anodic scan shows that there are two oxidative processes. A similar anodic response has been observed for zinc in the EG eutectic. In the $\mathrm{Zn}$ case, the presence of two anodic processes was unambiguously ascribed to two different morphologies of metals being deposited and stripped using in situ atomic force microscopy. ${ }^{15}$ The less anodic stripping peak was found to be due to the deposition of nanodeposits whereas the more anodic peak was due to the deposition of bulk metal.

Figure 1 also shows that the shape of the Ni stripping peaks depends upon sweep rate in both liquids showing that the processes were kinetically slow. It should also be noted that the current on the anodic sweep is slow to return to zero, inferring that some material is strongly bound to the electrode surface.

\section{Chronocoulometry of $\mathrm{Ni}(\mathrm{II})$ in $\mathrm{ChCl}: 2 \mathrm{EG}$ and ChCl:2urea IL}

Figure 2 shows the charge/time transient for a $\mathrm{Pt}$ electrode immersed in a $\mathrm{ChCl}: 2 \mathrm{EG}$ and a $\mathrm{ChCl}$ :2urea IL containing $\mathrm{NiCl}_{2} \cdot 6 \mathrm{H}_{2} \mathrm{O}(20 \mathrm{mM})$ for a potential step from $+1 \mathrm{~V}$ (held for $10 \mathrm{~s}$ ) to $-1 \mathrm{~V}$ for $30 \mathrm{~min}$. The charge/time transients are relatively linear but if the 


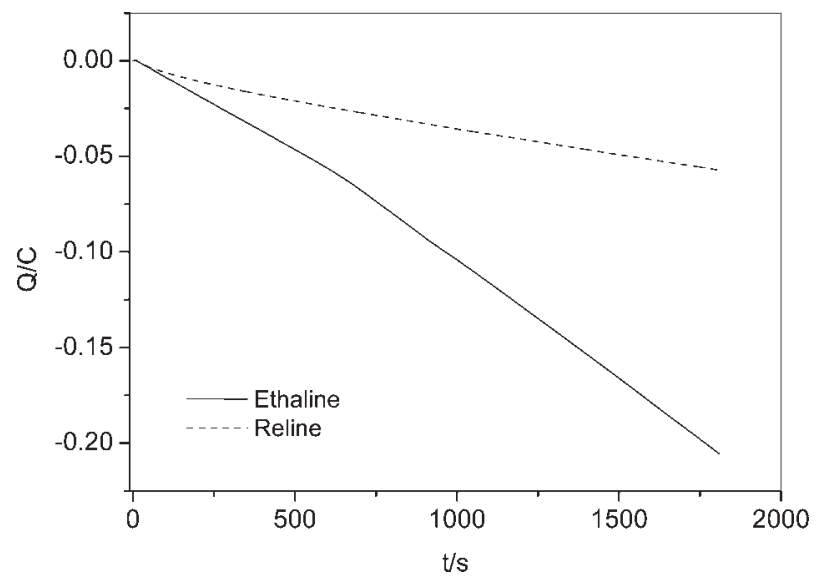

2 Charge/time transient for $\mathrm{Pt}$ electrode immersed in $\mathrm{ChCl}: 2 \mathrm{EG}$ and $\mathrm{ChCl}: 2$ urea IL containing $\mathrm{NiCl}_{2} \cdot 6 \mathrm{H}_{2} \mathrm{O}$ $(20 \mathrm{mM}$ ) for potential step from $+1 \mathrm{~V}$ (held for $10 \mathrm{~s}$ ) to $-1 \mathrm{~V}$ for $30 \mathrm{~min}$

processes are $100 \%$ current efficient, the slopes of the curves should be proportional to the diffusion coefficients of the two Ni complexes. A similar response was observed for copper and the ratio of the $\mathrm{d} Q / \mathrm{d} t$ plots was exactly the same as the ratio of the diffusion coefficients (obtained from the $\mathrm{Cu}^{2+/+}$ redox couple) showing that the deposition process is mass transport limited. No similar internal redox couple exists for $\mathrm{Ni}$ but it is reasonable to assume that $\mathrm{NiCl}_{3}{ }^{+}$has a similar diffusion coefficient to $\mathrm{CuCl}_{3}{ }^{+}$. The ratio $\mathrm{d} Q / \mathrm{d} t$ plots in Fig. 2 was found to be $5: 1$, which is significantly smaller than to the ratio of $D(10 \cdot 6)$. This analysis assumes that the process is $100 \%$ current efficient which is clearly not valid since gassing can be observed at the cathode. It was observed that both ILs decomposed at about the same potential as Ni was reduced.

\section{Bulk deposition of $\mathrm{Ni}(\mathrm{II})$ in $\mathrm{ChCl}: 2 \mathrm{EG}$ and ChCl:2urea IL}

Figure 3 shows SEM and AFM images of Ni deposited from $\mathrm{ChCl}: 2 \mathrm{EG}$ and $\mathrm{ChCl}: 2$ urea at an applied potential of $2.5 \mathrm{~V}$ (in a two electrode cell) for $120 \mathrm{~min}$. Both samples were dark grey deposits but the sample prepared from $\mathrm{ChCl}$ :2EG was slightly lighter in colour and AFM analysis showed that it was less rough than that obtained from $\mathrm{ChCl}$ :2urea. In the $\mathrm{ChCl}$ :2urea deposit, a more nodular growth was observed. The deposit morphology is surprisingly similar to that observed by Gou and Sun.

\section{Addition of brighteners}

Very little work has been carried out in terms of the development of brighteners. It is clear from Fig. 3 that

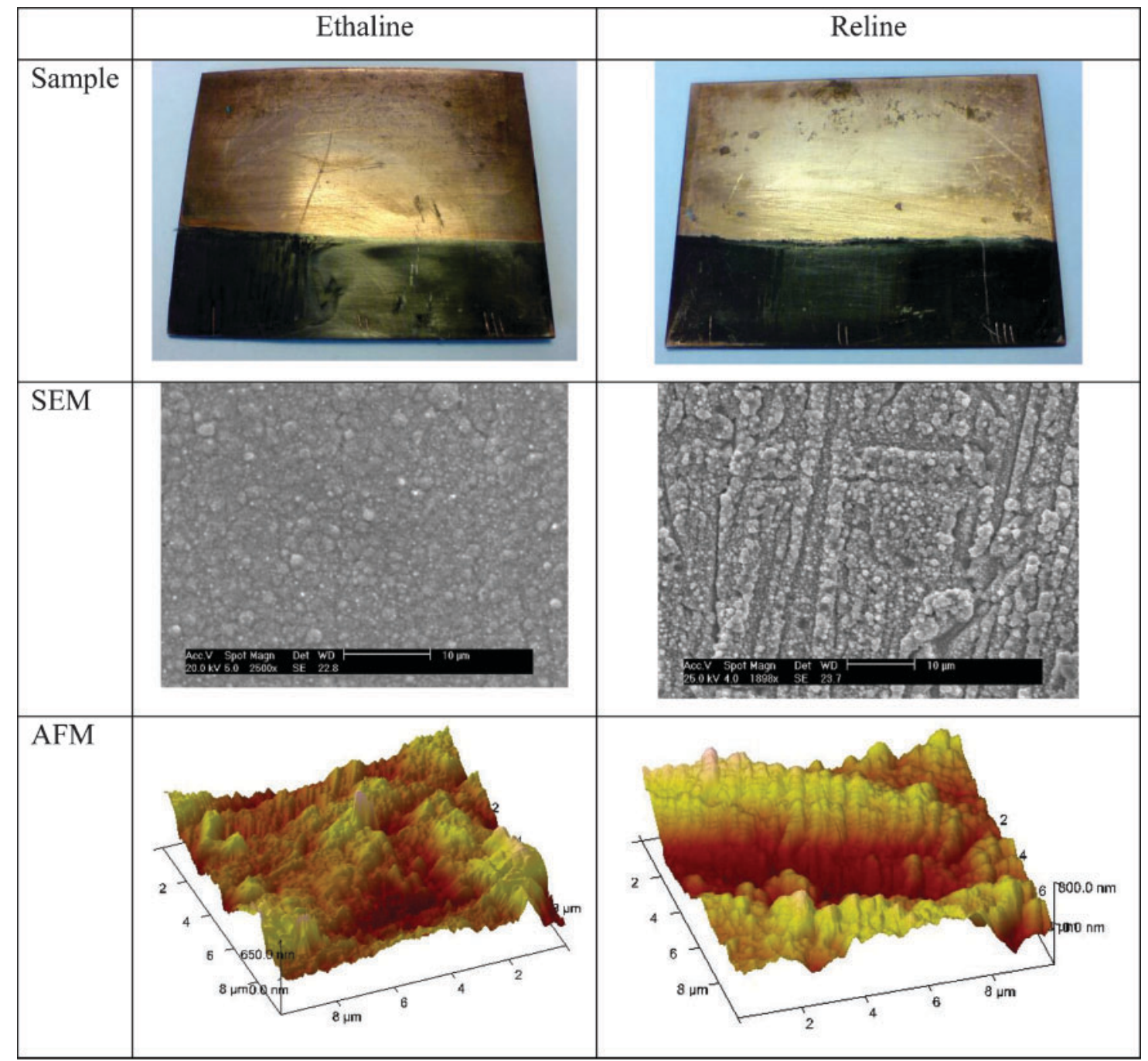

3 Photographs, SEM and AFM images of deposits obtained from electrolysis of $\mathrm{ChCl}: 2 \mathrm{EG}$ and $\mathrm{ChCl}: 2$ urea, both containing $0.2 \mathrm{~mol} \mathrm{dm}^{-3}$ at applied potential of $2.5 \mathrm{~V}$ for $120 \mathrm{~min}$ 

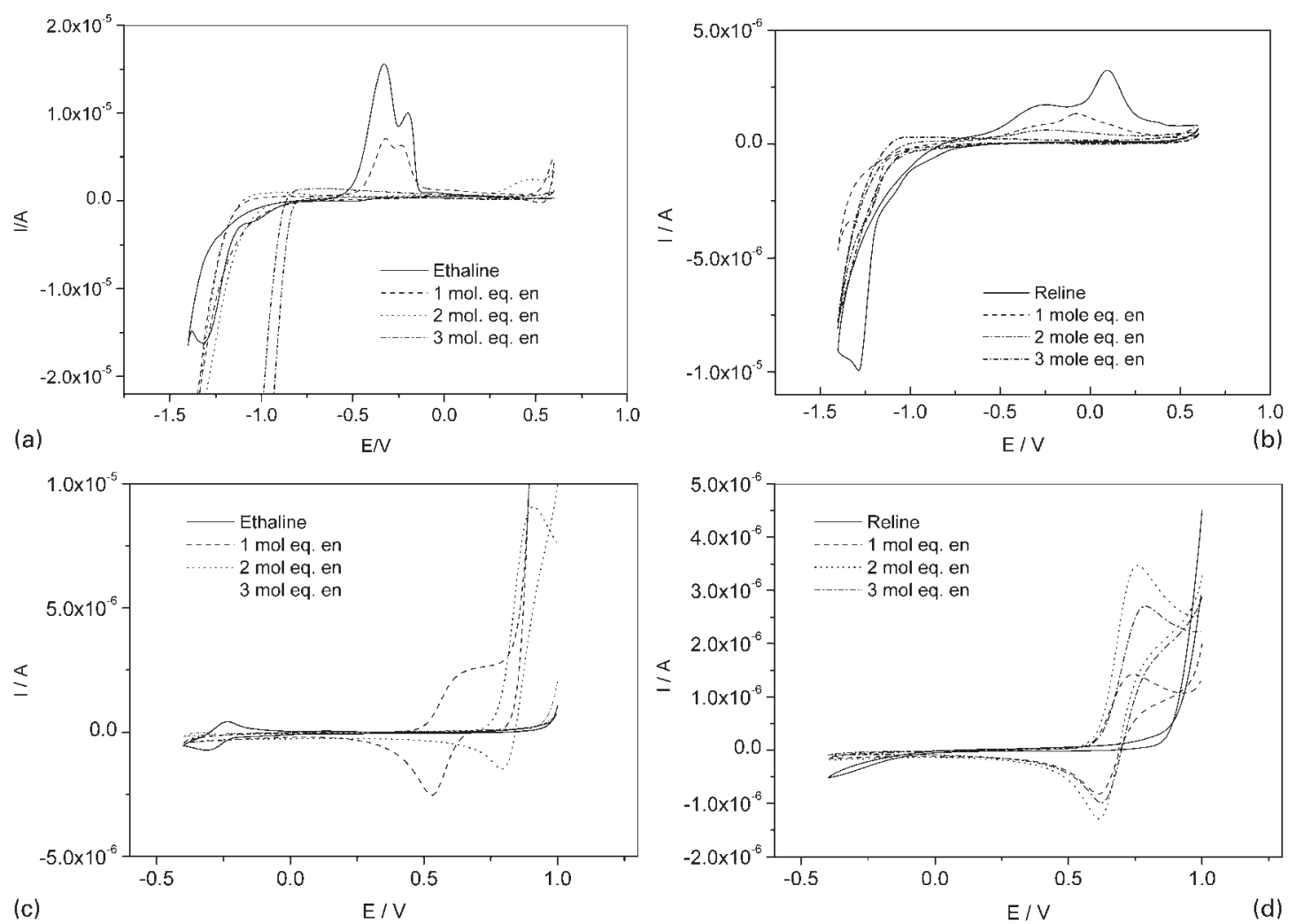

4 Cyclic voltammetry of $0.2 \mathrm{M} \mathrm{NiCl} 2 \cdot 6 \mathrm{H}_{2} \mathrm{O}$ in a ChCl:2EG and $c$ ChCl:2urea at $20^{\circ} \mathrm{C}$ on $\mathrm{Pt}$ electrode as function of sweep rate with various equivalents of en added: $b$ and $d$ correspond to UPD and anodic regions of scans for $a$ and $c$ respectively

the dull appearance of the deposit results from a relatively rough surface finish. To circumvent this issue, it would be preferable to produce smaller particle deposits. It has been recently shown by the authors that relatively strong complexing agents suppress the rate of metal growth and lead to finer particulate copper deposits. In this work, en and acac have been tested as possible brighteners for the nickel deposition process. ${ }^{2}$

Figure $4 a$ shows the cyclic voltammogram for $\mathrm{Ni}(\mathrm{II})$ in $\mathrm{ChCl}$ :2EG and the subsequent effect of mole equivalent additions of en. It is well known that en acts as a strong ligand for most transition metal ions. The aim of this experiment was to create a more stable $\mathrm{Ni}$ complex thus suppressing underpotential deposition (UPD) and decreasing the ability of the metal to nucleate. Figure $4 a$ shows that the cathodic process is relatively unaffected by the first two additions of en. The addition of the third mole equivalent of en leads to a large cathodic signal at ca. $-0.8 \mathrm{~V}$ which is probably due to the reduction of free en. Each addition of en greatly decreases the anodic response. This could be due to the decreased amount of deposition occurring when en is added. However when two mole equivalents of en are added, no stripping occurs, although bulk deposition experiments show that the $\mathrm{Ni}$ is still being deposited, suggesting that the presence of en affects the complex formed when the metal strips from the electrode surface. One possible explanation for this could be that the presence of en causes $\left[\mathrm{Ni}(\mathrm{en})_{3}\right]^{2+}$ to be formed and this could be difficult to strip from the electrode surface. This links with the results above showing that metals do not strip in an octahedral geometry. To discuss the effect of additives on the voltammetry of the $\mathrm{Ni}$, it is necessary to have an understanding of the species formed in solution when en is added.

FABMS for $\mathrm{NiCl}_{2}$ in $\mathrm{ChCl}$ :2EG shows peaks at 165 and 295 corresponding to $\mathrm{NiCl}_{3}{ }^{-}$and $\mathrm{Ni}_{2} \mathrm{Cl}_{5}{ }^{-}$respectively, all other signals were negligible and could not be identified. The data in $\mathrm{ChCl}$ :2urea showed only the peak at 165 . The relative intensities of these signals were relatively unchanged with the addition of 1,2 and 3 mole equivalents of en. In the absence of en, the main species present is apparently $\mathrm{NiCl}_{3}{ }^{-}$with a solution absorbance maxima at $415 \mathrm{~nm}$. This differs from the UV vis spectra of the aqueous solution of $\mathrm{NiCl}_{2} \cdot 6 \mathrm{H}_{2} \mathrm{O}$, indicating that the waters of hydration are not present on the metal centre. The addition of three equivalents of en produces a purple coloured liquid which has an absorbance spectrum that is similar to $\left[\mathrm{Ni}(\mathrm{en})_{3}\right]^{2+}$ in aqueous solution. However, the mass spectra of this solution still show that the dominant species is $\mathrm{NiCl}_{3}{ }^{-}$and the positive FAB does not show a signal for $\left[\mathrm{Ni}(\mathrm{en})_{3}\right]^{2+}$, it is however probable that both species are present in the solution and the likely explanation is that $\left[\mathrm{Ni}(\mathrm{en})_{3}\right]^{2+}$ is poorly ionised, or flies poorly in the FABMS. The UV vis and FABMS data for the ILs containing 1 and 2 equivalents of en are not conclusive although evidence of $\mathrm{NiCl}_{3}{ }^{-}$was again found. Weak signals at $\mathrm{m} / \mathrm{z}=223$ and 258 could not be explained, but clearly contained $\mathrm{Ni}$ from the isotopes splitting pattern. The UV vis spectra show a hybrid between $\mathrm{NiCl}_{3}{ }^{-}$and $\left[\mathrm{Ni}(\mathrm{en})_{3}\right]^{2+}$. It is possible that a variety of $\mathrm{Ni}$ containing complexes were present, but standard spectroscopic techniques could not elucidate their structures. It is, however clear just from the colour alone that the en changes speciation significantly. 


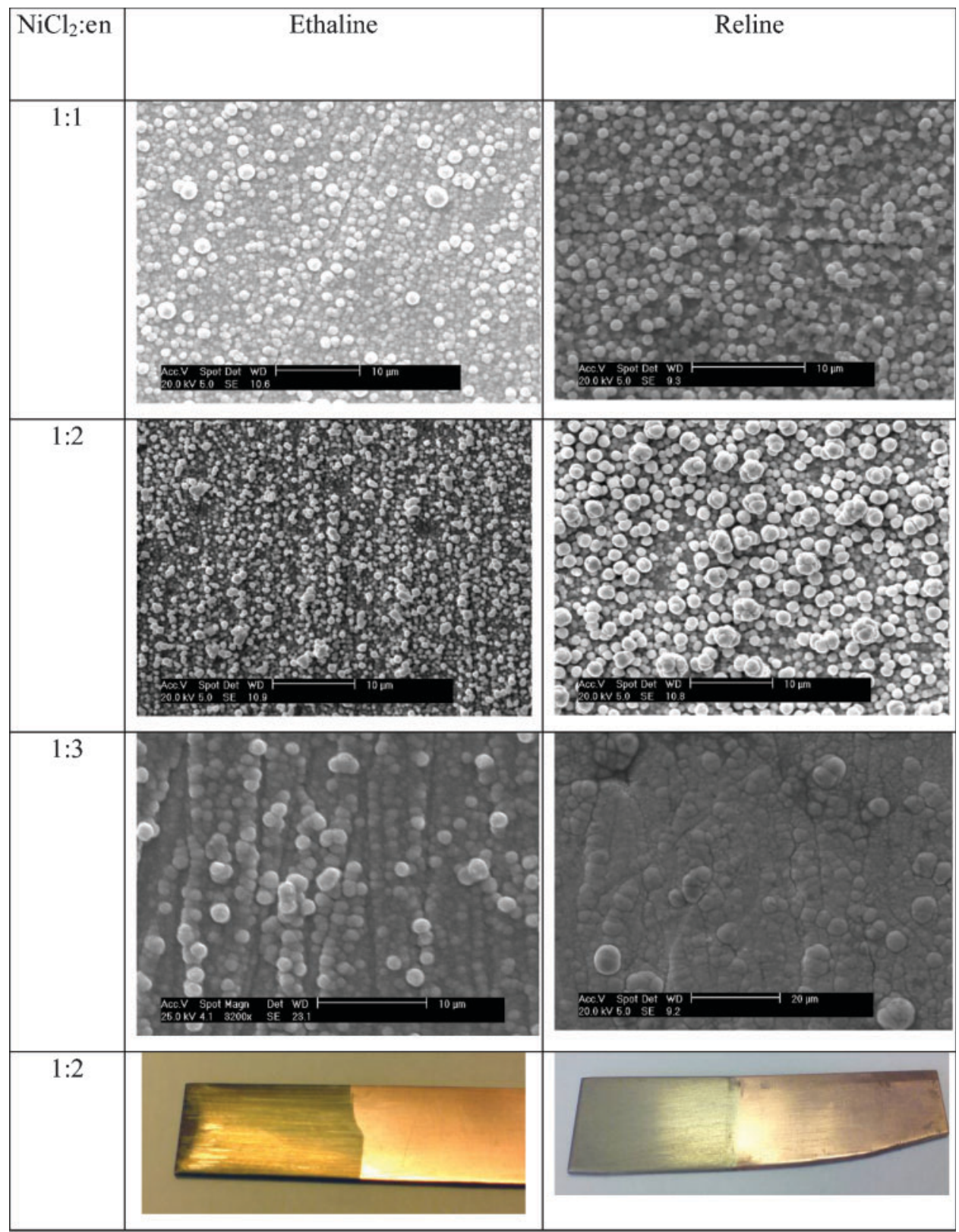

5 Scanning electron micrographs of $\mathrm{Ni}$ deposited on $\mathrm{Cu}$ from solution containing $0.2 \mathrm{~mol} \mathrm{dm}^{-3} \mathrm{NiCl}_{2} .2 \mathrm{H}_{2} \mathrm{O}$ in both Ethaline and Reline with various mole equivalents of en

Figure $4 b$ shows that without en present, the anodic sweep shows no oxidation process (without prior deposition of $\mathrm{Ni}$ ) within the potential window of the solvent, but UPD is observed. When 1 equivalent of en is added, an apparent one electron oxidation process occurs at $\sim 0.56 \mathrm{~V}$. A second equivalent of en shifts the redox potential wave positive to $0.92 \mathrm{~V}$. It is proposed that this process corresponds to the oxidation of the $\mathrm{Ni}$ centre from $\mathrm{Ni}^{2+}$ to $\mathrm{Ni}^{3+}$. While this is not common for $\mathrm{Ni}$ complexes, it has previously been reported for en complexes. The addition of a third equivalent of en suppresses the oxidation behaviour of the solution. The addition of en suppresses the UPD of $\mathrm{Ni}$. It has previously been shown for $\mathrm{Zn}$ that the amount of UPD material increases the amount of microcrystalline material and suppresses the growth of nanocrystallites. ${ }^{15}$

In $\mathrm{ChCl}$ :2urea, a similar response was observed to that in $\mathrm{ChCl}$ :2EG with a slight difference in oxidative behaviour. An oxidative current was observed even when two equivalents of en were added, although the current is comparatively small. Figure $4 c$ shows the voltammetry for the oxidative sweep between -0.4 and $+1 \mathrm{~V}$. A one electron oxidation which again corresponds to the conversion of $\mathrm{Ni}^{2+}$ to $\mathrm{Ni}^{3+}$ can be seen at $0.5 \mathrm{~V}$ on the anodic sweep (Fig. $4 d$ ). Surprisingly, the redox potential is not changed by the amount of en added; however, the redox current decreases as 2 eq. $>3$ eq. $>1$ eq. of en was added. This suggests a series of equilibria that occur where only one species is electroactive. The FABMS and UV vis data suggest that this species is neutral and either square planar or tetrahedral. Hence, formation of $\left[\mathrm{Ni}(\mathrm{en})_{3}\right]^{2+}$ suppresses the oxidation of $\mathrm{Ni}^{2+}$ because the octahedral complex is not redox active.

Comparison of the chronocoulometry data for the ILs with and without the addition of en shows that when en is added, there is a significant decrease in current and the associated growth rate will also be decreased, suggesting 


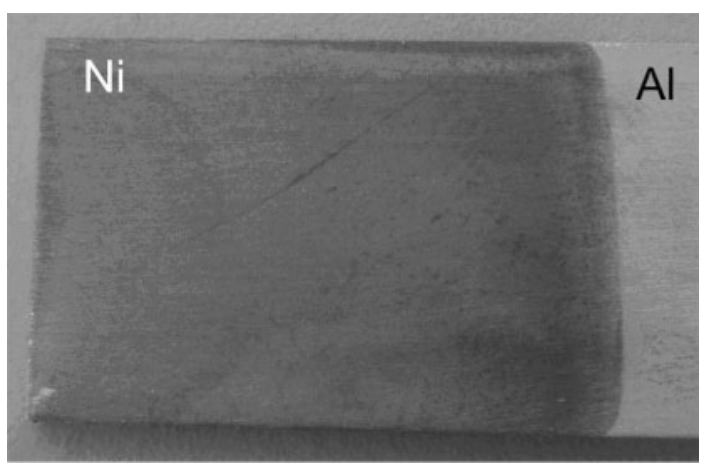

6 Photograph of nickel layer deposited onto aluminium substrate following electrolysis of $\mathrm{ChCl}: 2 \mathrm{EG}$ containing $0.2 \mathrm{~mol} \mathrm{dm}^{-3}$ with 3 mole equivalents of en at applied potential of $2.5 \mathrm{~V}$ for $120 \mathrm{~min}$ that the en stops the formation and growth of Ni nuclei. It was also found that after the addition of en, the process was no longer mass transport limited, indicating that the growth mechanism had changed. AFM images were obtained of $\mathrm{Ni}$ deposited onto $\mathrm{Cu}$ substrates by holding at $2 \cdot 30 \mathrm{~V}$ for $2 \mathrm{~h}$ from both $\mathrm{ChCl}: 2 \mathrm{EG}$ and $\mathrm{ChCl}$ :2urea. Comparing these images with those obtained in the absence of en, it was seen that significantly smaller crystallites were obtained when en is present. The crystallites were more regular showing that nucleation was more difficult.

Figure 5 shows SEM images of deposits from liquids with different mole equivalents of en. The Ni deposit from $\mathrm{ChCl}$ :2EG without the addition of en was black and consisted of particles of varying sizes. The addition of en led to a wider distribution of particle sizes and

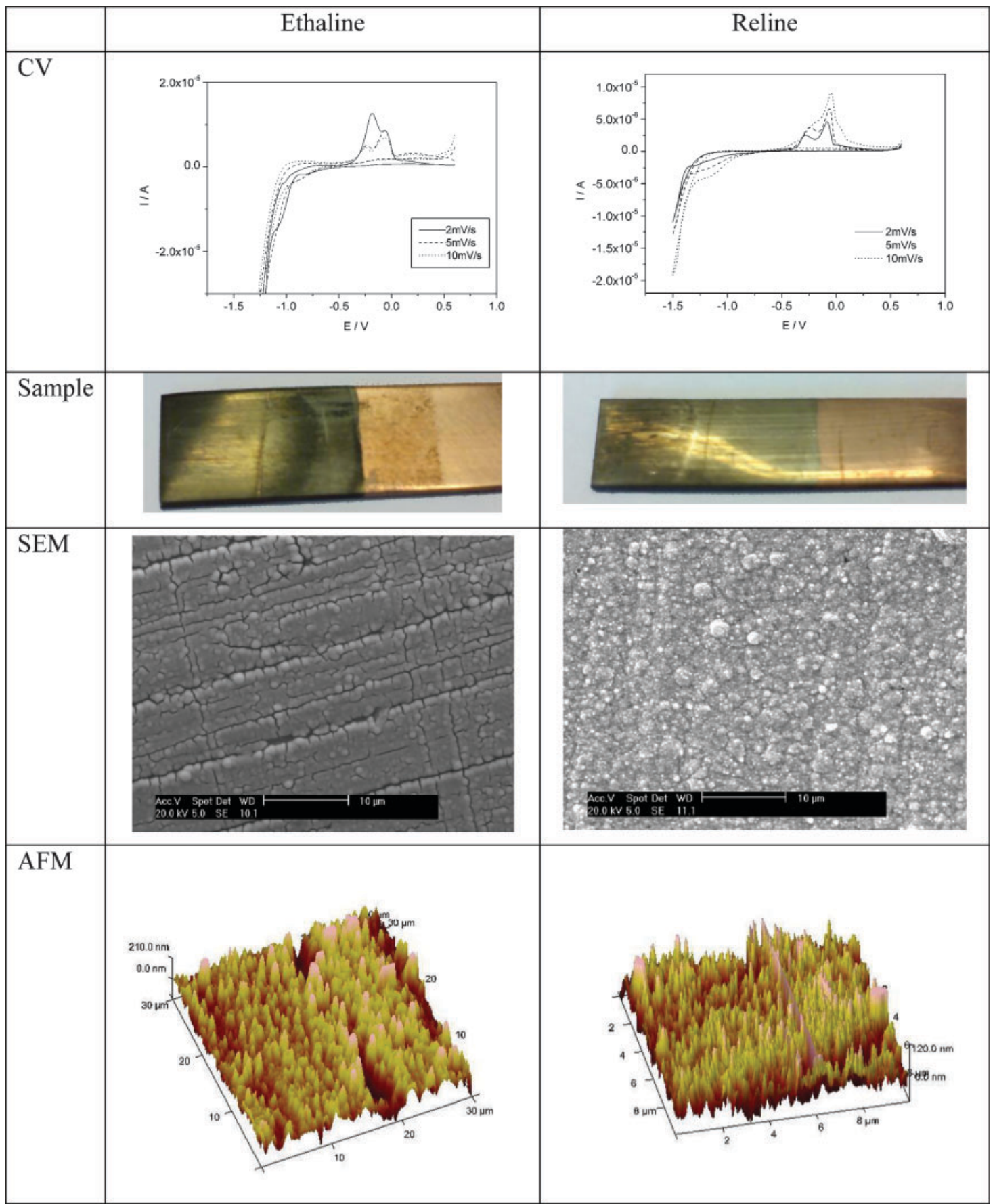

7 Cyclic voltammograms, photographs, SEM and AFM images of deposits obtained from electrolysis in ChCl:2EG and $\mathrm{ChCl}$ :2urea both containing $0.2 \mathrm{~mol} \mathrm{dm}^{-3}$ with three equivalents of acac at applied potential of $2.5 \mathrm{~V}$ for $120 \mathrm{~min}$ 
greater levelling of the surface, resulting in dull grey deposits. Further addition of en decreased the small scale surface roughness. In fact, although some of the features appear to be larger as a consequence of adding more en (Fig. 5), these larger features are made up from clusters of much smaller crystallites. The images for the addition of the same mole equivalent of en in $\mathrm{ChCl}$ :2urea are similar to those obtained for $\mathrm{ChCl}$ :2EG, although the deposits appeared optically brighter. This difference in brightness could be partially due to the fact that the coatings are thinner. In conclusion, the SEM images do however show that the surfaces were significantly smoother with the addition of en. It can be seen that en suppresses UPD and nucleation, and therefore leads to a smoother surface finish.

One advantage of ionic liquids listed above is the ability to deposit metals onto substrates that usually passivate or are water sensitive. Figure 6 shows a photograph of an aluminium sample which was coated directly in a similar manner to the copper samples shown above. The relatively dull appearance is a consequence of the rough substrate that was used.

\section{Acac}

The effect of adding sodium acetylacetonate as a complexing agent to both $\mathrm{ChCl}: 2 \mathrm{EG}$ and $\mathrm{ChCl}$ :2urea was investigated and compared with the results for the addition of en. The cyclic voltammograms for the two ionic liquids are shown in Fig. 7. In $\mathrm{ChCl}: 2 \mathrm{EG}$, the acac complex shifts the cathodic signal ca. $-1 \cdot 22 \mathrm{~V}$ less negative whereas the anodic peak remains relatively unaffected with two oxidative processes still observed. FABMS results are unclear with $\mathrm{NiCl}_{3}{ }^{-}$still the dominant signal but unidentified $\mathrm{Ni}$ containing fragments at 369 and 486.

In $\mathrm{ChCl}$ :2urea, the cathodic peak is more negative than that in $\mathrm{ChCl}$ :2EG but the anodic signal is relatively similar. FABMS shows that $\mathrm{NiCl}_{3}{ }^{-}$is the dominant species, a signal at 269 corresponding to $\left[\mathrm{Ni}(\mathrm{acac}) \mathrm{Cl}_{2}\right]^{-}$ which is not observed in $\mathrm{ChCl}$ :2EG but the signal at 369 is also present The SEM images of the deposits in Fig. 7 confirm that in comparison to deposits from acac, much brighter deposits are obtained when en is present.

\section{Conclusions}

Eutectic base ionic liquids $\mathrm{ChCl}$ :2EG and $\mathrm{ChCl}$ :2urea can be used for the electrodeposition of nickel. FABMS shows that the major species present is $\mathrm{NiCl}_{3}^{-}$. For deposition of $\mathrm{Ni}$, the shape of the stripping peaks depends upon sweep rates, illustrating that the process is kinetically slow. The morphology and composition can be changed by the judicious choice of IL and the addition of complexing agents such as en and acac as brighteners. Both additives suppress UPD of $\mathrm{Ni}$ and lead to smaller particulate deposits. The direct deposition of nickel on aluminium was observed for the first time.

\section{References}

1. F. Endres: Chem. Phys. Chem., 2002, 3, 144.

2. A. P. Abbott and K. J. McKenzie: Phys. Chem. Chem. Phys., 2006, 8, 4265 .

3. H. Ohno (ed.): 'Electrochemical aspects of ionic liquids'; 2005, New York, John Wiley and Sons.

4. F. Endres: Z. Phys. Chem., 2004, 218, 255.

5. F. Endres and S. Zein El Abedin: Phys. Chem. Chem. Phys., 2006, 8, 2101.

6. F. Endres, A. P. Abbott and D. R. MacFarlane: 'Electrodeposition of metals using ionic liquids'; 2008, Weinheim, Wiley-VCH.

7. S.-P. Gou and I.-W. Sun: Electrochim. Acta, 2008, 53, 2538-2544.

8. A. P. Abbott, G. Capper, D. L. Davies, R. Rasheed and V. Tambyrajah: Chem. Commun., 2003, 70.

9. A. P. Abbott, D. Boothby, G. Capper, D. L. Davies and R. Rasheed: J. Am. Chem. Soc., 2004, 126, 9142.

10. A. P. Abbott, G. Capper, K. J. McKenzie and K. S. Ryder: J. Electroanal. Chem., 2007, 599, 288.

11. A. P. Abbott, S. Nandhra, S. Postlethwaite, K. S. Ryder and E. L. Smith: Phys. Chem. Chem. Phys., 2007, 9, 3735-3743.

12. A. P. Abbott, J. Griffith, S. Nandhra, C. O'Connor, S. Postlethwaite, K. S. Ryder and E. Smith: Surf. Coat. Technol., 2008, 202, 2033-2039.

13. A. P. Abbott, G. Capper, B. Swain and D. Wheeler: Trans. IMF, $2005,82,51-54$.

14. A. P. Abbott, G. Capper, K. J. McKenzie and K. S. Ryder: Electrochim. Acta, 2006, 51, 4420-4425.

15. A. P. Abbott, J. C. Barron and K. S. Ryder: Electrochem. Acta, 2008, to be published. 